Gut, 1984, 25, 1100-1102

\title{
Comparison of the Eder-Puestow and Celestin techniques for dilating benign oesophageal strictures
}

\author{
K R HINE, C J HAWKEY, M ATKINSON, AND G K T HOLMES \\ From the University Hospital, Queen's Medical Centre, Nottingham; and Derbyshire Royal Infirmary, Derby
}

SUMmaRY The Celestin and Eder-Puestow methods of dilating benign oesophageal strictures have been compared prospectively in a randomised trial. One hundred and thirty three dilatations were performed on 72 patients. There was no significant difference between the two techniques with regard to the long term relief of symptoms. Celestin dilatation was quicker, less likely to cause pharyngeal trauma, and less damaging to guide wires. It could not be used, however, in those patients in whom only a short length of guide wire could be passed through the stricture.

Dilatation of the oesophagus is an established technique for the treatment of benign strictures and as a prelude to the intubation of malignant lesions. ${ }^{1}$ The use of a guide wire, placed through the stricture at endoscopy and over which the dilators are passed, has greatly increased the safety of the procedure. ${ }^{2}$ The Eder-Puestow metal olive dilators have been in use for many years and the method entails the successive passage of up to 12 olives each mounted on a separate stem, to a maximum diameter of 15-18 $\mathrm{mm}$. Multiple dilatations are required in $60 \%$ of patients. ${ }^{3}$ The method described by Celestin and Campbell uses only two tapered dilators made from Neoplex, a firm but pliable material, ${ }^{4}$ with maximum diameters of 12 and $18 \mathrm{~mm}$ respectively and the tapered portion is $20 \mathrm{~cm}$ in length.

The aim of the present study was to compare prospectively the Eder-Puestow method with the Celestin technique.

\section{Methods}

PATIENTS

One hundred and thirty three dilatations were carried out on 72 patients ( 37 women, 35 men) with benign oesophageal strictures drawn from two hospitals. The dilatations were carried out by one of the four authors and randomisation between the two methods was done using sealed envelopes opened only after the insertion of the guide wire. The Eder-Puestow (EP) method was used in 69 and the

Address for correspondence: Dr Keith R Hine, Department of Medicine. University Hospital, Queen's Medical Centre, Nottingham NG7 2UH.

Received for publication 9 December 1983
Celestin (C) in 64 patients. One hundred patients $(50 \mathrm{EP} ; 50 \mathrm{C})$ were dilated using sedation with intravenous benzodiazepine and a local anaesthetic spray to the pharynx. Twenty four (15 EP; nine C) also received intravenous pethidine (invariably given before randomisation). Nine patients (4 EP; 5 C) were dilated under general anaesthesia because of the patient's expected intolerance to dilatation under sedation, for example, in those patients who were mentally handicapped.

Radiological screening was only performed when the stricture would not allow the passage of a paediatric endoscope. Each dilatation was timed from the stage at which the guide wire was in place to the completion of dilatation. The degree of dilatation was thei decision of the operator although most patients were dilated to at least $16 \mathrm{~mm}$ (50 FG) irrespective of the preoperative diameter of the stricture.

After dilatation each patient was re-examined endoscopically to determine if a perforation of the oesophagus had been sustained or if there had been trauma to the upper oesophagus or pharynx. A semi-quantitative grading of the degree of dysphagia (Table 1) was made before and one month after dilatation. A record was also kept of the subsequent need for further dilatation and a symptom free interval was calculated.

\section{Results}

The groups treated by the Eder-Puestow or the Celestin method were comparable in the preoperative grade of dysphagia (Table 1), the number 
Table 1 Grades of dysphagia

\begin{tabular}{|c|c|c|c|c|}
\hline \multirow[b]{3}{*}{ Grade } & \multicolumn{3}{|c|}{ Patients (no) } & \\
\hline & \multicolumn{2}{|c|}{ Eder-Puestow } & \multicolumn{2}{|c|}{ Celestin } \\
\hline & Preop & $\begin{array}{l}1 \text { month } \\
\text { postop }\end{array}$ & Preop & $\begin{array}{l}1 \text { month } \\
\text { postop }\end{array}$ \\
\hline 0 (none) & 0 & 28 & 0 & 24 \\
\hline 1 (avoiding certain foods) & 27 & 23 & 17 & 23 \\
\hline 2 ('sloppy' diet) & 28 & 9 & 32 & 10 \\
\hline 3 (fluids only) & 12 & 4 & 15 & 1 \\
\hline 4 (complete) & 2 & 0 & 0 & 0 \\
\hline Operative failure & - & 3 & - & 3 \\
\hline Recurrence of dysphagia & & & & $?$ \\
\hline No follow up information & - & $\begin{array}{l}0 \\
2\end{array}$ & - & $\begin{array}{l}2 \\
1\end{array}$ \\
\hline
\end{tabular}

of previous dilatations (Table 2), the characteristics of the stricture (Table 2) and the type of medication used. The assigned technique of dilatation failed on six occasions, three Eder-Puestow and three Celestin. The three Celestin failures occurred because insufficient wire could be passed distal to the stricture to accommodate the leading part of the dilators. All three were subsequently successfully dilated using the Eder-Puestow dilators under radiological control. Two Eder-Puestow failures occurred because there was repeated kinking of the wire in the oropharynx and the tight fit of the dilators on the wire precluded their passage into the oesophagus. Both patients were successfully dilated with the Celestin dilators which have a looser fit on the wire and ride kinks more effectively. The third EderPuestow failure was in a patient who became violent under midazolam sedation and the stricture was successfully dilated by the Eder-Puestow method under general anaesthesia.

One perforation occurred in this study, in a patient undergoing Celestin dilatation. It was at the level of the stricture and the patient recovered fully with conservative management. Four patients had

Table 2 Characteristics of stricture

\begin{tabular}{|c|c|c|}
\hline & Eder-Puestow & Celestin \\
\hline $\begin{array}{l}\text { Distance from teeth }(\mathrm{cm}) \\
\text { median (range) }\end{array}$ & $\begin{array}{l}30 \\
(18-43)\end{array}$ & $\begin{array}{l}34 \\
(18-40)\end{array}$ \\
\hline $\begin{array}{l}\text { Diameter (mm) } \\
\text { median (range) }\end{array}$ & $\begin{array}{l}9 \\
(1-12)\end{array}$ & $\begin{array}{l}8 \\
(3-12)\end{array}$ \\
\hline $\begin{array}{l}\text { Length (cm) } \\
\text { median (range) }\end{array}$ & $\begin{array}{l}1 \\
(0 \cdot 5-10.0)\end{array}$ & $\begin{array}{l}1 \\
(0 \cdot 5-9 \cdot 0)\end{array}$ \\
\hline \multicolumn{3}{|l|}{ Previous dilatations (no) } \\
\hline 0 & 12 & 18 \\
\hline $1-2$ & 22 & 17 \\
\hline $3-4$ & 14 & 14 \\
\hline$>4$ & 21 & 15 \\
\hline
\end{tabular}

pharyngeal bleeding after dilatation and all had been dilated using the Eder-Puestow olives. There were no other complications and no deaths.

The Celestin technique was significantly quicker than the Eder-Puestow method. The mean time taken to complete Celestin dilatation was 1 minute 42 seconds compared with 4 minutes 25 seconds for the Eder-Puestow method $(\mathrm{p}<0.001)$ (unpaired $t$ test).

Thirty guide wires were damaged (to render unusable) by the Eder-Puestow technique but only two by the Celestin method. This difference was highly significant $\left(\chi^{2}=27 \cdot 7, p<0 \cdot 001\right)$.

Symptomatic relief of dysphagia one month after dilatation was broadly comparable in the two groups (Table 1). The estimated curves of the symptom free interval after dilatation (computed by life table analysis) showed no significant difference between the techniques $(p>0.5$ Mantel-Haenszel test) (Figure).

\section{Discussion}

Our study has shown that the Celestin and EderPuestow techniques of dilating benign oesophageal strictures are equally effective in providing longterm relief of symptoms. Although it was claimed that the Celestin method carried a lower incidence of radial splitting and hence might be expected to give longer lasting relief of dysphagia, ${ }^{4}$ our study has not borne this out.

The Celestin technique of dilatation is, however,

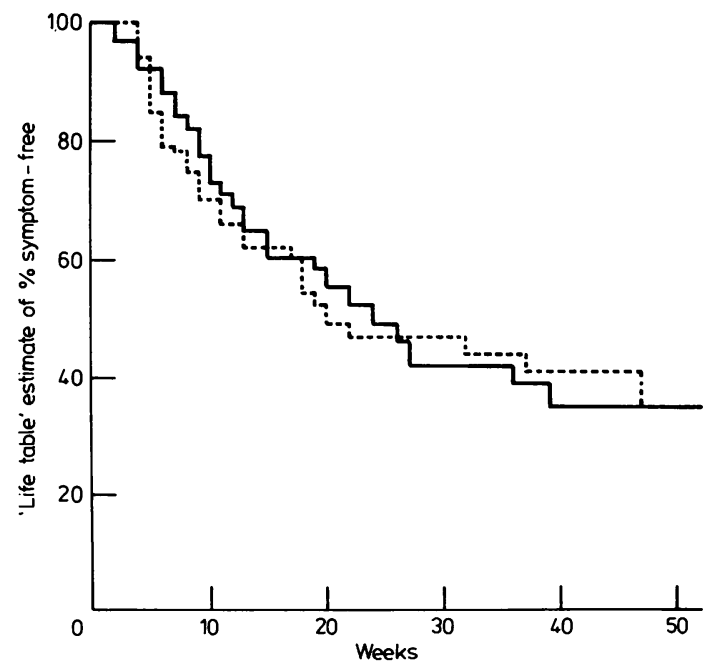

Figure Estimated curves of the symptom-free interval (computed by life table analysis) in patients dilated by the Celestin (-) and Eder-Puestow (- - ) techniques. 
easier and quicker than the Eder-Puestow procedure. Only two dilators have to be used whereas up to 12 manipulations are required with the Eder-Puestow method. With fewer instruments passing through the pharynx it might be expected that there would be less pharyngeal trauma and this was so in our series. The reduced number of manipulations required may also partly account for the fewer guide wires that were damaged with Celestin dilatation although tightness of fit of the dilator onto the wire and flexibility of the leading edge of the dilators were probably also important factors. The replacement of guide-wires was the most significant revenue expenditure in this study, indicating an advantage for Celestin dilatation. Capital costs are also less with the Celestin dilators.

Two disadvantages of the Celestin technique became apparent during this study. Firstly, the leading part of the dilator requires at least $20 \mathrm{~cm}$ of free wire beyond the stricture to allow its maximum diameter to engage the stricture. Occasionally insufficient length of wire could be passed through the stricture, for example, because of hold up of the wire tip in a hiatal hernia beyond. In our study, this resulted in three failures, and all three were subsequently dilated successfully with the Eder-Puestow olives. Secondly, the operator's 'feel' of the dilatation is very distinctive when using the EderPuestow system but this is impaired with the tapered Celestin dilators. Furthermore, as the stem of the large dilator is $18 \mathrm{~mm}$ in diameter it was difficult to distinguish on occasions between resistance of the stricture and resistance caused by the teeth. This second problem could be overcome by modifying the large dilator so that its stem is smaller in diameter.

The study has confirmed the safety and effectiveness of both the Eder-Puestow and Celestin methods for dilating benign oesophageal strictures. Providing sufficient guide wire can be passed through the stricture, the choice of dilators may rest with the operator's subjective preference tempered by financial considerations with regard to damaged guide wires.

\section{References}

1 Weisel W, Raine F, Watson RR, Frederick JJ. Palliative treatment of oesophageal carcinoma: a method and its evaluation. Ann Surg 1959; 149: 207-16.

2 Puestow KL. Conservative treatment of stenosing disease of the oesophagus. Postgrad Med 1955; 18: 6-14.

3 Ogilvie AL, Ferguson R, Atkinson M. Outlook with conservative treatment of peptic oesophageal stricture. Gut 1980; 21: 23-5.

4 Celestin LR, Campbell WB. A new and safe system for oesophageal dilatation. Lancet 1981; 1: 74-5. 